\title{
Iatrogenic spondylolisthesis following laminectomy for degenerative lumbar stenosis: systematic review and current concepts
}

\author{
Daipayan Guha, MD, ${ }^{1}$ Robert F. Heary, MD, ${ }^{3}$ and Mohammed F. Shamji, MD, PhD ${ }^{1,2}$ \\ 'Department of Surgery, University of Toronto; '2Division of Neurosurgery, Toronto Western Hospital, Toronto, Ontario, Canada; \\ and ${ }^{3}$ Rutgers New Jersey Medical School, Newark, New Jersey
}

\begin{abstract}
OBJECT Decompression without fusion for degenerative lumbar stenosis is an effective treatment for both the pain and disability of neurogenic claudication. latrogenic instability following decompression may require further intervention to stabilize the spine. The authors review the incidence of postsurgical instability following lumbar decompression, and assess the impact of surgical technique as well as study design on the incidence of instability.
\end{abstract}

METHODS A comprehensive literature search was performed to identify surgical cohorts of patients with degenerative lumbar stenosis, with and without preexisting spondylolisthesis, who were treated with laminectomy or minimally invasive decompression without fusion. Data on patient characteristics, surgical indications and techniques, clinical and radiographic outcomes, and reoperation rates were collected and analyzed.

RESULTS A systematic review of 24 studies involving 2496 patients was performed, assessing both open laminectomy and minimally invasive bilateral canal enlargement. Postoperative pain and functional outcomes were similar across the various studies, and postoperative radiographic instability was seen in $5.5 \%$ of patients. Instability was seen more frequently in patients with preexisting spondylolisthesis $(12.6 \%)$ and in those treated with open laminectomy (12\%). Reoperation for instability was required in $1.8 \%$ of all patients, and was higher for patients with preoperative spondylolisthesis $(9.3 \%)$ and for those treated with open laminectomy (4.1\%).

CONCLUSIONS Instability following lumbar decompression is a common occurrence. This is particularly true if decompression alone is selected as a surgical approach in patients with established spondylolisthesis. This complication may occur less commonly with the use of minimally invasive techniques; however, larger prospective cohort studies are necessary to more thoroughly explore these findings.

http://thejns.org/doi/abs/10.3171/2015.7.FOCUS15259

KEY WORDS instability; laminectomy; lumbar stenosis; spondylolisthesis

$\mathrm{S}$ YMPTOMATIC lumbar spinal stenosis (LSS) can cause progressive neurogenic claudication, radicular pain, and weakness. Surgical intervention can provide for improvements in pain, disability, and health-related quality of life..$^{49}$ The pathoanatomy underlying the cross-sectional narrowing of the vertebral canal includes varying degrees of disc herniation and/or bulging, zy goapophyseal facet joint hypertrophy and cyst formation, and ligamentum flavum hypertrophy and buckling. In some cases, the degenerative disc disease permits spondylolisthesis as well. ${ }^{4,24}$ Neural element compression can cause neurogenic claudication from central canal stenosis or radiculopathy from lateral recess encroachment. Superimposed mechanical back symptoms may occur secondary to dynamic instability.
Although surgical decompression for neurogenic claudication has been shown to be efficacious, the role of fusion remains less clear. In certain subgroups, particularly those with degenerative spondylolisthesis or dynamic instability, there has been suggestion of benefit. ${ }^{18,25,42}$ Preoperative patient assessment prognosticating for postoperative instability may include overt instability or facet and disc morphology where decompression would be expected to cause iatrogenic instability. ${ }^{43,44}$ Segmental spinal stability is compromised by the very nature of the surgical approach, with the likelihood of excessive motion augmented when wider decompressions are performed, greater ligamentous disruption occurs, or multiple levels are included. ${ }^{11,31}$ Indeed, postlaminectomy instability is one of the most common indications for reoperation following decompres-

ABBREVIATIONS LSS = lumbar spinal stenosis; MIS = minimally invasive surgery; ODI = Oswestry Disability Index.

SUBMITTED May 26, 2015. ACCEPTED July 10, 2015.

INCLUDE WHEN CITING DOI: 10.3171/2015.7.FOCUS15259. 
sion. ${ }^{23,36}$ Minimally invasive surgery (MIS) techniques for the spine purport, among other advantages, to preserve the posterior osseoligamentous structures, and may minimize destabilization while achieving adequate decompression of the neural elements. ${ }^{2,28,30,37,39,47,54}$ Critics of MIS techniques note the possibility of inadequate decompression with some of these procedures..$^{51}$

The goal of this review was to evaluate the incidence of postlaminectomy instability among patients with LSS who were symptomatic with neurogenic claudication, and whose condition was managed by decompression without fusion. The objectives were to compare the relative incidences of this complication by surgical technique and also to assess whether the reported rates of instability were affected by study design.

\section{Illustrative Case}

A patient was referred to the senior author with symptomatic flexion-induced radicular leg pain and paraspinal muscle spasm following a posterior lumbar decompression for neurogenic claudication. This 45-year-old man presented 3 months after L4-5 laminectomy and discectomy for left L-5 radiculopathy, with positional bilateral claudicant symptoms and disabling mechanical back pain. His symptoms were exacerbated by flexion, with dynamic spinal imaging demonstrating translational instability on supine to upright transition. Further investigations revealed the cause, with Fig. 1A - an axial CT scan-revealing the extensive decompression involving removal of the left L-4 inferior articular process. Revision decompression and transforaminal lumbar interbody fusion (Fig. 1B and C) provided him with a good clinical result for both back and leg symptoms.

\section{Methods}

We conducted a systematic search in MEDLINE, EMBASE, Scopus, Web of Science, and Google Scholar for literature published through May 2015, limiting the search results to human studies published in the English language. Search terms included "neurogenic claudication," "lumbar spinal stenosis," "decompression," "laminectomy," and "surgery," as well as derivatives therefrom. Reference lists of key articles were also systematically checked to identify additional eligible articles. The specific question asked focused on the incidence of postlaminectomy instability and whether it was variable by surgical technique, the presence of preoperative spondylolisthesis, and how instability was variably reported by retrospective and prospective studies. Case reports or case series that consisted of fewer than 10 patients were excluded. Other works that were excluded were animal, cadaveric, and biomechanical studies. Figure 2 summarizes this selection process.

Studies were included if a minimum mean follow-up of 12 months was achieved and reporting of pre- and postoperative sagittal lumbar alignment and reoperation rates was included. When multiple studies were found from the same cohort, only the report with the longer follow-up was included. Patients who were treated with fusion at the index operation were excluded from analysis.

\section{Data Extraction}

We extracted the following data from the included articles: study design, patient demographic information, diagnosis, and surgical procedure. From these studies, we also compiled the reported outcomes of new or progressive spondylolisthesis (radiographic findings), and of reoperation for postoperative instability (clinical findings). Furthermore, clinical outcomes extracted from the studies included those used by 3 or more studies: the Physical Function and Bodily Pain components of the 36-Item Short Form Health Survey, the Japanese Orthopaedic Association lumbar score, ${ }^{26}$ the Oswestry Disability Index (ODI), and the visual analog scale for back and leg pain. Bias was assessed at the study level by using the Cochrane Risk of Bias tool, with each study thereafter assigned a grade of evidence reported in Table 1 alongside study characteristics.

\section{Data Analysis}

Because of the variable mechanisms of neurological outcome reporting, clinical outcomes were described in a systematic review format, with pooled estimates for dichotomous outcomes where feasible. Summary statistics regarding overall reported complication rates of instability and reoperation for stabilization were generated by pooled estimates based on study size. Two-factor weighted nominal logistic regression analysis was performed to define the dependence of both radiographic translational listhesis and repeated spinal operation for stabilization on the
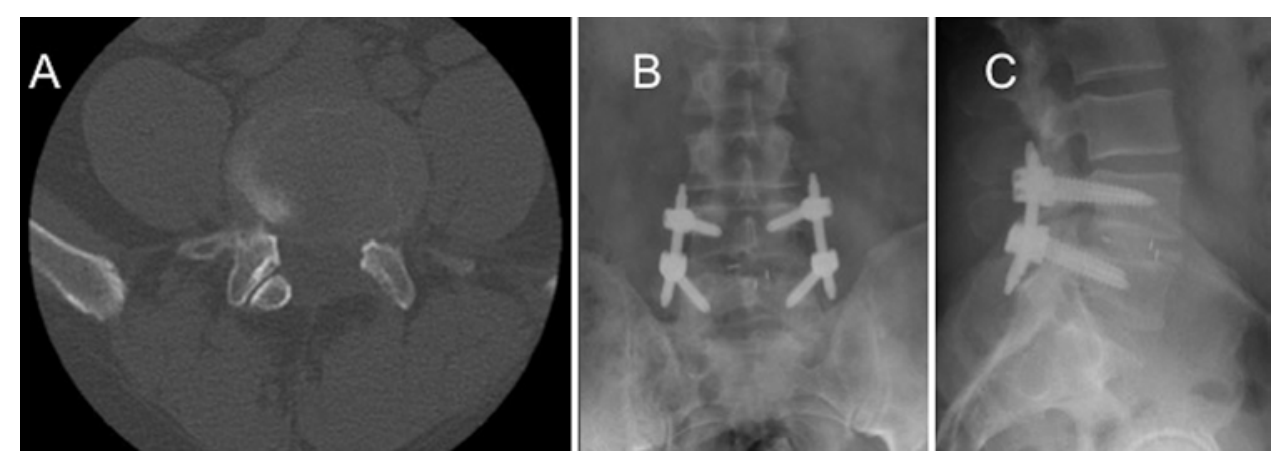

FIG. 1. Postlaminectomy axial CT scan (A) reveals extensive lateral decompression with resection of the left inferior articular process of $\mathrm{L}-4$. Postoperative anteroposterior (B) and lateral (C) radiographs show acceptable alignment of instrumentation after a transforaminal lumbar interbody fusion. 


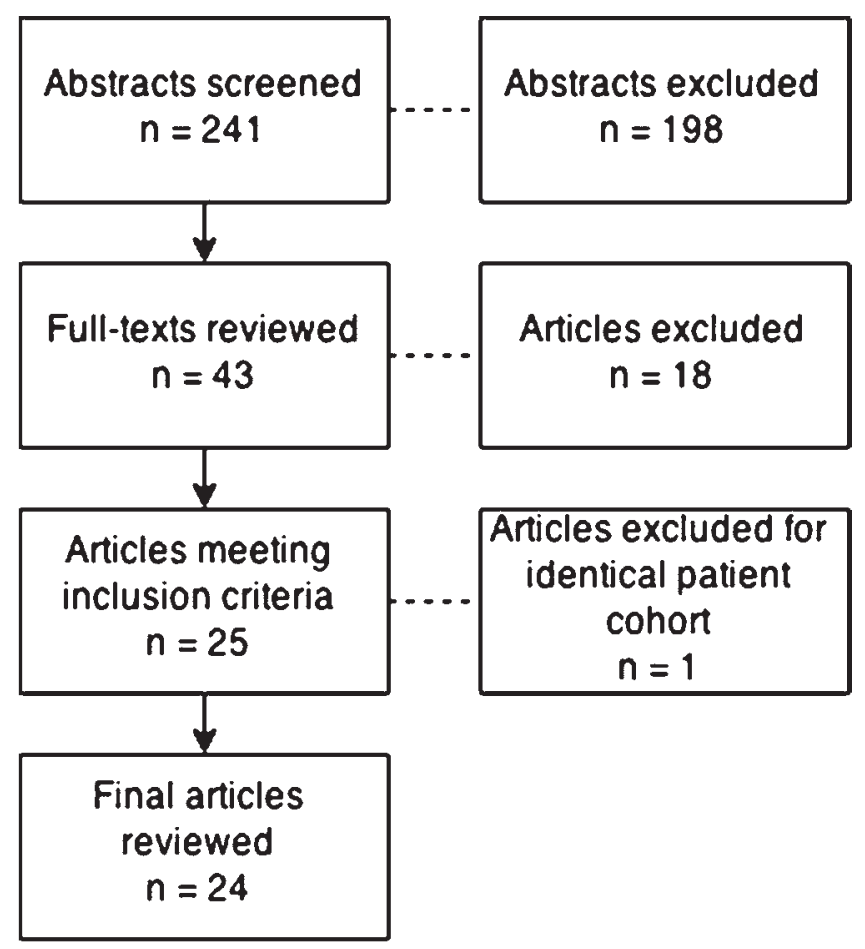

FIG. 2. Study selection flowchart of the search for articles pertaining to surgical management of LSS and incidence of postoperative instability.

presence of preoperative spondylolisthesis versus stenosis alone and the use of MIS versus open surgical intervention. The 0.05 level of significance was used with post hoc Tukey's analysis.

\section{Results \\ Study Characteristics}

The search strategy yielded 241 relevant citations, of which 198 were excluded based on title and/or abstract. Forty-three were selected for full-text review, of which 18 more were excluded due to lack of postoperative radiographic data in 11 studies, inclusion of only patients undergoing fusion in 6, or follow-up period less than 12 months in 1. Twenty-five papers were considered appropriate, of which 2 publications reported on differing follow-ups of the same cohort, ${ }^{33,49}$ so only the study with the longer follow-up was included. The flow of this process defining the final 24 studies is shown in Fig. 2, and the fundamental characteristics are shown in Table 1.

Fifteen of the studies were conducted prospective$1 y^{1,5-8,15,16,21,32,33,35,37,46,47,52}$ and 9 were conducted retrospectively. ${ }^{10,14,19,20,27,38-41}$ Postoperative instability was defined variably across studies, including increase in sagittal translation between flexion-extension radiographs by 2 $\mathrm{mm},{ }^{1,8,14} 3 \mathrm{~mm},{ }^{16} 5 \mathrm{~mm},{ }^{47} 5 \%,{ }^{21}$ or $8 \%,{ }^{19}$ or an increase in sagittal angulation by more than $15^{\circ}$ between flexion and extension. ${ }^{41}$ Reoperation rates were considered positive if the procedure was explicitly cited to be a fusion for instability, although studies rarely stated the specific indication motivating such fusion. Furthermore, reoperation for residual stenosis was not consistently reported across the studies reviewed herein.

\section{Patient Characteristics}

Table 2 summarizes the pooled characteristics of all the study patients. The mean patient age was 65.7 years, and $51 \%$ were male. The radiographic pattern was reportedly stenosis only in $42 \%$ of cases, stenosis and spondylolisthesis in $11 \%$ of cases, and the remainder was not defined between the two. Following surgical intervention, the mean follow-up across all studies was 43.5 months; 37.1 months for prospective studies and 54.1 months for retrospective studies.

\section{Clinical Outcomes}

Pooled clinical outcomes are summarized in Table 3. More than $50 \%$ improvement after surgery was seen in all metrics across the total cohort. Patients with stenosis exhibited greater improvement in ODI scores than those with both stenosis and spondylolisthesis, although both groups reached the minimum clinically important difference for improvement. Outcomes between open laminectomy and minimally invasive procedures were similar across all outcome measures.

\section{Radiographic Progression and Reoperation}

Table 4 delineates the radiographic outcome of progressive deformity and the incidence of reoperation. The overall incidence of new or increased postoperative spondylolisthesis was $5.5 \%$, with a reoperation rate for instability of $1.8 \%$, roughly one-third of patients in whom radiographic slip was detected. The radiographic progression was seen nearly twice as frequently in patients with preoperative Grade I-II spondylolisthesis compared with those having stenosis alone.

Retrospective studies reported the incidence of radiographic progression at $6.8 \%$ compared with $6.5 \%$ for prospective studies. There was a higher incidence of progression among patients with preexisting spondylolisthesis $(17 \%)$ versus stenosis alone $(5.3 \%, \mathrm{p}<0.001)$ and among patients in whom open decompression was performed (13\%) compared with minimally invasive decompression $(3.2 \%, \mathrm{p}<0.001)$. Reoperation rates were likewise similar between retrospective (1.2\%) and prospective (2.3\%) studies. There was a higher incidence of reoperation among patients with preexisting spondylolisthesis (8.9\%) versus stenosis alone $(1.1 \%, \mathrm{p}<0.001)$ and among patients in whom open decompression was performed (11\%) compared with a minimally invasive decompression $(0.7 \%, \mathrm{p}$ $<0.001)$.

\section{Discussion}

Lumbar spinal stenosis is predominantly a disease of the elderly, and the most common indication for spine surgery in patients older than 65 years. ${ }^{9}$ Surgical decompression for symptomatic disease has been shown to improve quality-of-life outcomes in multiple randomized and nonrandomized trials; ${ }^{3,34,50}$ however, there remains no consensus on the optimal surgical technique. In the US alone there is significant regional variation in technique, specifically whether to perform an arthrodesis. ${ }^{48}$ Despite relative stability of the overall number of operations performed, there is a nationwide trend in the US increasingly toward 
TABLE 1. Literature review of studies on degenerative lumbar stenosis

\begin{tabular}{|c|c|c|c|c|c|c|c|}
\hline Authors \& Year & Study Design & $\begin{array}{l}\text { No. of } \\
\text { Pts }\end{array}$ & $\begin{array}{l}M / F \\
(\%)\end{array}$ & $\begin{array}{c}\text { Mean Age } \\
\text { (yrs) }\end{array}$ & $\begin{array}{c}\text { Mean FU } \\
\text { (mos) }\end{array}$ & Definition of Instability & Grade of Evidence ${ }^{*}$ \\
\hline Lurie et al., 2015 & Prospective & 358 & $62: 38$ & 63.9 & 96.0 & Not defined & High (High) \\
\hline Nomura et al., 2014 & Retrospective & 124 & $59: 41$ & 71.0 & 31.0 & Increased translation & Very Low (Low - 1) \\
\hline Chang et al., 2014 & Prospective & 165 & $57: 43$ & 68.7 & 40.0 & Increased translation (>2 mm) & Moderate $($ High - 1) \\
\hline Arai et al., 2014 & Prospective & 94 & $62: 38$ & 68.8 & 24.0 & Increased translation (>2 mm) & Moderate $($ High - 1) \\
\hline Minamide et al., 2013 & Prospective & 310 & $48: 52$ & 68.7 & 24.0 & Increased translation & Low (High - 2) \\
\hline Blumenthal et al., 2013 & Prospective & 40 & $25: 75$ & 68.2 & 43.0 & Not defined & High (High) \\
\hline Morgalla et al., 2011 & Retrospective & 108 & $47: 53$ & 71.0 & 12.0 & Not defined & Very Low (Low - 1) \\
\hline Hong et al., 2011 & Retrospective & 53 & $53: 47$ & 62.4 & 49.3 & Flex/ext translation (>8\%) & Low (Low) \\
\hline Celik et al., 2010 & Prospective & 71 & $46: 54$ & 60.0 & 60.0 & Flex/ext translation (>4 mm) & Moderate $($ High - 1) \\
\hline Kelleher et al., 2010 & Retrospective & 75 & $52: 48$ & 68.0 & 47.5 & Increased translation (>6\%) & Low (Low) \\
\hline Yagi et al., 2009 & Prospective & 41 & $34: 66$ & 72.1 & 18.2 & Not defined & Low (High - 2) \\
\hline Castro-Menendez et al., 2009 & Prospective & 50 & $58: 42$ & 56.0 & 48.0 & Not defined & Moderate $($ High - 1) \\
\hline Fu et al., 2008 & Prospective & 152 & $46: 54$ & 57.6 & 40.0 & Not defined & Moderate $($ High - 1) \\
\hline Ikuta et al., 2008 & Prospective & 37 & $35: 65$ & 69.0 & 38.0 & $\begin{array}{l}\text { Flex/ext translation }(>5 \%) \text { or angulation } \\
\qquad\left(>5^{\circ}\right)\end{array}$ & Moderate (High - 1) \\
\hline Ofluoğlu et al., 2007 & Retrospective & 34 & $41: 59$ & 57.5 & 23.0 & Flex/ext angulation $\left(>15^{\circ}\right)$ & Low (Low) \\
\hline Costa et al., 2007 & Retrospective & 374 & $49: 51$ & 64.7 & 30.3 & Not defined & Very Low (Low - 1) \\
\hline Oertel et al., 2006 & Retrospective & 102 & $55: 45$ & 63.4 & 67.2 & Not defined & Low (Low) \\
\hline Lin et al., 2006 & Prospective & 18 & $50: 50$ & 67.0 & 14.0 & Not defined & Moderate $($ High - 1) \\
\hline Thomé et al., 2005 & Prospective & 120 & $44: 56$ & 68.0 & 15.5 & Flex/ext translation (>5 mm) & Moderate $($ High - 1) \\
\hline Ghogawala et al., 2004 & Prospective & 20 & $32: 68$ & 68.8 & 12.0 & Flex/ext translation (>3 mm) & Moderate $($ High - 1) \\
\hline Mariconda et al., 2002 & Prospective & 22 & $27: 73$ & 62.6 & 47.0 & Panjabi/White criteria & Moderate $($ High - 1) \\
\hline Iguchi et al., 2000 & Retrospective & 37 & $51: 49$ & 60.9 & 157.2 & Increased translation (>3 mm) & Low (Low) \\
\hline Thomas et al., 1997 & Prospective & 26 & NR & 68.0 & 36.7 & Not defined & High (High) \\
\hline Fox et al., 1996 & Retrospective & 95 & $52: 48$ & 67.5 & 69.6 & Flex/ext translation (>2 mm) & Low (Low) \\
\hline
\end{tabular}

Flex/ext = flexion/extension; FU = follow-up; NR = not reported; pts = patients.

* Grade-i.e., quality of evidence-is stated; the initial quality assessment and any modifiers are stated in parentheses.

complex fusion, which is associated with 2-3 times the upfront cost and often higher subsequent reoperation rates than decompression alone. ${ }^{12,13,29}$ Reflective of the lack of consensus, surgeon preference often outweighs patient clinical and radiographic factors as the primary determinant for whether fusion is performed. ${ }^{22,25}$

Postoperative instability after lumbar decompression remains one of the primary motivators of arthrodesis performed during the index procedure, or in reoperations after decompression. ${ }^{23}$ The incidence of postdecompression instability varies widely in the literature, ranging from $0 \%$ to $63 \%, 1,14$ due partly to the lack of standardized radiographic criteria. ${ }^{53}$ In our review alone, 10 of 24 studies reported incidences of postoperative instability without specifying its definition; the remaining studies varied widely in their stated criteria. Patient heterogeneity also contributes to the variability in postoperative instability. Multiple observational studies have combined patients with and without preexisting degenerative spondylolisthesis, although the influence of preexisting spondylolisthesis on subsequent instability remains debatable. ${ }^{16}$

Biomechanical work has demonstrated increased segmental mobility following disruption of the posterior osseoligamentous structures in bilateral laminectomy. ${ }^{17,45}$ Several MIS procedures intended to preserve the posterior tension band have been developed over the past 2 decades. The few existing studies directly comparing an MIS technique to open laminectomy have demonstrated superiority in pain and functional status, along with reduced blood loss, length of hospital stay, and cost, at relatively short fol-

TABLE 2. Summary of characteristics in patients with degenerative lumbar stenosis

\begin{tabular}{lc}
\hline \multicolumn{1}{c}{ Variable } & Value \\
\hline Age in yrs, mean \pm SD & $65.7 \pm 4.7$ \\
\hline$\%$ M/F & $51: 49$ \\
\hline Surgical indication & $1039(42 \%)$ \\
\hline Stenosis & $285(11 \%)$ \\
\hline Stenosis \& spondylolisthesis & $1172(47 \%)$ \\
\hline Undefined & $777(31 \%)$ \\
\hline Surgical technique & $189(7.5 \%)$ \\
\hline Laminectomy & $947(37 \%)$ \\
\hline Spinous process-splitting laminectomy & $417(17 \%)$ \\
\hline Open ULBD & $196(7.8 \%)$ \\
\hline Endoscopic ULBD
\end{tabular}

$\mathrm{ULBD}=$ unilateral laminotomy with bilateral decompression. 

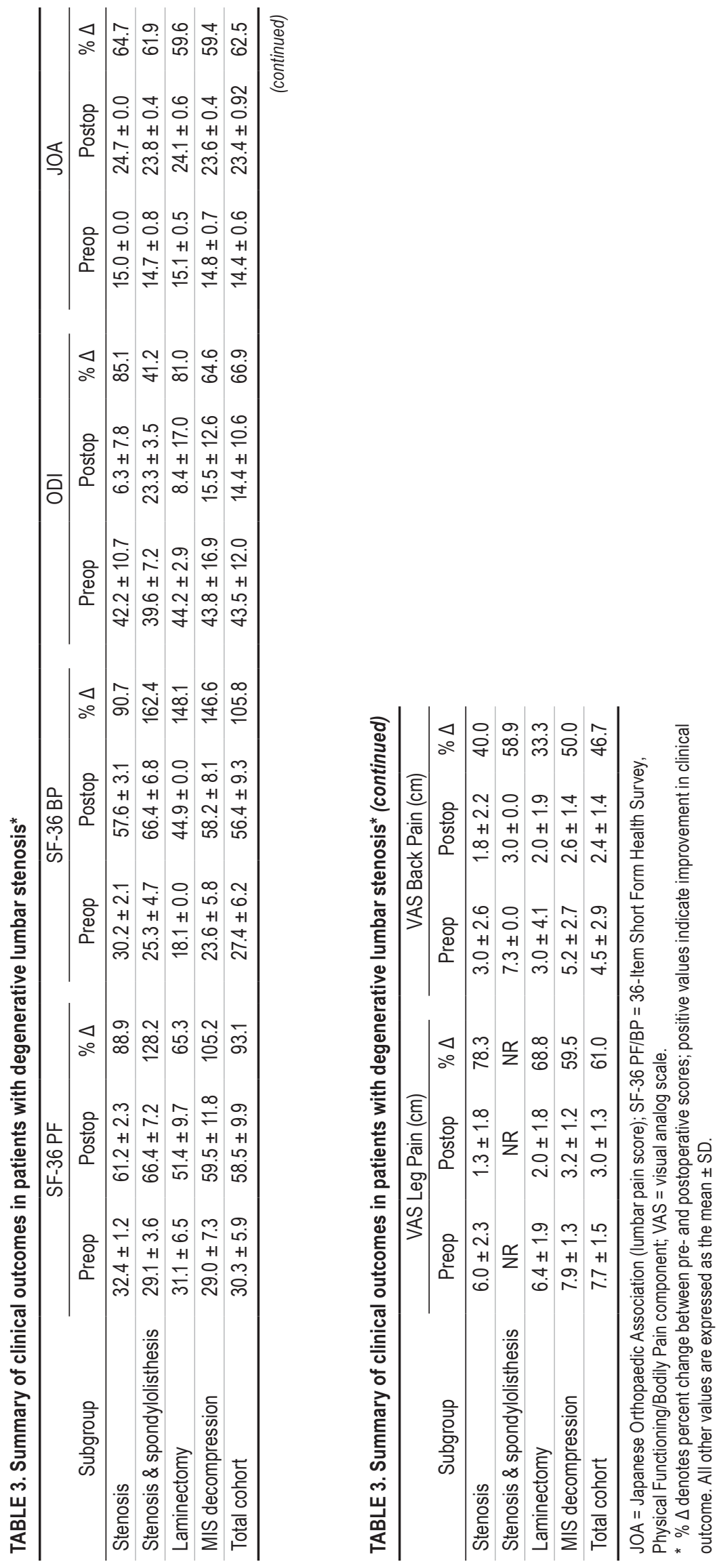
TABLE 4. Summary of patient outcomes for radiographic progression and need for stabilization surgery

\begin{tabular}{lcc}
\hline \multicolumn{1}{c}{ Subgroup } & $\begin{array}{c}\text { New/Increased } \\
\text { Spondylolisthesis at } \\
\text { Mean FU (\% of pts) }\end{array}$ & $\begin{array}{c}\text { Reop for Postop } \\
\text { Instability } \\
\text { (\% of pts) }\end{array}$ \\
\hline Stenosis & $6.8 \%$ & $0.72 \%$ \\
\hline Stenosis \& spondylolisthesis & $12.6 \%$ & $9.3 \%$ \\
\hline Laminectomy & $12.0 \%$ & $4.1 \%$ \\
\hline MIS decompression & $2.6 \%$ & $0.81 \%$ \\
\hline Total cohort & $5.5 \%$ & $1.8 \%$ \\
\hline
\end{tabular}

low-up intervals. ${ }^{15,46,47,52}$ Our review suggests no significant differences in clinical outcomes between MIS techniques and open laminectomy, although postoperative instability and reoperation rates were consistently reported to be lower for the less invasive techniques. What remains unclear is whether MIS approaches are associated with higher rates of reoperation for residual stenosis that was not adequately addressed in the indexed operation. Regrettably, the studies included in this analysis do not address acutely residual stenosis and cannot answer the question of surgical quality beyond the equivalence of reported clinical outcomes.

No significant differences in postoperative instability or reoperation rate were found between studies conducted prospectively or retrospectively in our review. Retrospective studies had a longer mean follow-up duration of 54.1 months, relative to 37.1 months for prospective studies, during which additional reoperative cases might be expected. However, the quality of follow-up in these retrospective series was often poor, with postoperative radiographs usually performed only in symptomatic patients. Because randomized controlled trials are also difficult with a heterogeneous patient group, studies of large, population-based, prospectively observed cohorts are required to identify significant predictors of radiographic and clinical outcomes in the neurogenic claudication population. ${ }^{29}$

\section{Study Limitations}

This is a narrative review of retrospective and prospective clinical studies, in which the patient management was nonrandomized, subject to surgeon assessment of patient candidacy for secondary surgical intervention, and with unpredictable recording of complications. It is nevertheless reassuring that many of the complication rates for these studies are in line with magnitudes observed in reported national databases. The cost burden of this complication has not been rigorously addressed by any of the reviewed literature, and should be included in future prospective work so that both the patient outcome and economic burden are understood in the context of lumbar decompressive surgery. In parallel, though, the potential for postlaminectomy instability must be ruled in or out in the workup of every patient who has persistent postoperative pain following structurally decompressive spinal surgery before the diagnosis of failed back surgery syndrome or persistent postoperative neuropathic pain can be assigned.

\section{Conclusions}

Iatrogenic instability following decompression for symptomatic LSS occurs in 5\%-6\% of patients. Interestingly, the rates reported have been consistent between both prospective and retrospective studies. Patients with preoperative spondylolisthesis undergoing decompression are nearly 10 times more likely to undergo a subsequent additional stabilization procedure than their stenosis-only counterparts. Minimally invasive surgical procedures may help protect patients from this complication, although more prospective studies with longer follow-up durations are necessary to better define whether this theoretical benefit will be realized in the longer term.

\section{References}

1. Arai Y, Hirai T, Yoshii T, Sakai K, Kato T, Enomoto M, et al: A prospective comparative study of 2 minimally invasive decompression procedures for lumbar spinal canal stenosis: unilateral laminotomy for bilateral decompression (ULBD) versus muscle-preserving interlaminar decompression (MILD). Spine (Phila Pa 1976) 39:332-340, 2014

2. Aryanpur J, Ducker T: Multilevel lumbar laminotomies: an alternative to laminectomy in the treatment of lumbar stenosis. Neurosurgery 26:429-433, 1990

3. Atlas SJ, Deyo RA, Keller RB, Chapin AM, Patrick DL, Long JM, et al: The Maine Lumbar Spine Study, Part III. 1-year outcomes of surgical and nonsurgical management of lumbar spinal stenosis. Spine (Phila Pa 1976) 21:1787-1795, 1996

4. Bae HW, Rajaee SS, Kanim LE: Nationwide trends in the surgical management of lumbar spinal stenosis. Spine (Phila Pa 1976) 38:916-926, 2013

5. Blumenthal C, Curran J, Benzel EC, Potter R, Magge SN, Harrington JF Jr, et al: Radiographic predictors of delayed instability following decompression without fusion for degenerative grade I lumbar spondylolisthesis. J Neurosurg Spine 18:340-346, 2013

6. Castro-Menendez M, Bravo-Ricoy JA, Casal-Moro R, Hernandez-Blanco M, Jorge-Barreiro FJ: Midterm outcome after microendoscopic decompressive laminotomy for lumbar spinal stenosis: 4-year prospective study. Neurosurgery 65:100-110, A12, 2009

7. Celik SE, Celik S, Göksu K, Kara A, Ince I: Microdecompressive laminatomy with a 5-year follow-up period for severe lumbar spinal stenosis. J Spinal Disord Tech 23:229235, 2010

8. Chang HS, Fujisawa N, Tsuchiya T, Oya S, Matsui T: Degenerative spondylolisthesis does not affect the outcome of unilateral laminotomy with bilateral decompression in patients with lumbar stenosis. Spine (Phila Pa 1976) 39:400-408, 2014

9. Ciol MA, Deyo RA, Howell E, Kreif S: An assessment of surgery for spinal stenosis: time trends, geographic variations, complications, and reoperations. J Am Geriatr Soc 44:285-290, 1996

10. Costa F, Sassi M, Cardia A, Ortolina A, De Santis A, Luccarell G, et al: Degenerative lumbar spinal stenosis: analysis of results in a series of 374 patients treated with unilateral laminotomy for bilateral microdecompression. J Neurosurg Spine 7:579-586, 2007

11. Dai L, Cheng P, Tu K, Xu Y, Zhang W: The effect of posterior element resection on the stress distribution in the lumbar spine. Chin Med Sci J 10:113-115, 1995

12. Deyo RA, Martin BI, Kreuter W, Jarvik JG, Angier H, Mirza SK: Revision surgery following operations for lumbar stenosis. J Bone Joint Surg Am 93:1979-1986, 2011

13. Deyo RA, Mirza SK, Martin BI, Kreuter W, Goodman DC, Jarvik JG: Trends, major medical complications, and charges 
associated with surgery for lumbar spinal stenosis in older adults. JAMA 303:1259-1265, 2010

14. Fox MW, Onofrio BM, Onofrio BM, Hanssen AD: Clinical outcomes and radiological instability following decompressive lumbar laminectomy for degenerative spinal stenosis: a comparison of patients undergoing concomitant arthrodesis versus decompression alone. J Neurosurg 85:793-802, 1996

15. Fu YS, Zeng BF, Xu JG: Long-term outcomes of two different decompressive techniques for lumbar spinal stenosis. Spine (Phila Pa 1976) 33:514-518, 2008

16. Ghogawala Z, Benzel EC, Amin-Hanjani S, Barker FG II, Harrington JF, Magge SN, et al: Prospective outcomes evaluation after decompression with or without instrumented fusion for lumbar stenosis and degenerative Grade I spondylolisthesis. J Neurosurg Spine 1:267-272, 2004

17. Gillespie KA, Dickey JP: Biomechanical role of lumbar spine ligaments in flexion and extension: determination using a parallel linkage robot and a porcine model. Spine (Phila Pa 1976) 29:1208-1216, 2004

18. Herkowitz HN, Kurz LT: Degenerative lumbar spondylolisthesis with spinal stenosis. A prospective study comparing decompression with decompression and intertransverse process arthrodesis. J Bone Joint Surg Am 73:802-808, 1991

19. Hong SW, Choi KY, Ahn Y, Baek OK, Wang JC, Lee SH, et al: A comparison of unilateral and bilateral laminotomies for decompression of L4-L5 spinal stenosis. Spine (Phila Pa 1976) 36:E172-E178, 2011

20. Iguchi T, Kurihara A, Nakayama J, Sato K, Kurosaka M, Yamasaki K: Minimum 10-year outcome of decompressive laminectomy for degenerative lumbar spinal stenosis. Spine (Phila Pa 1976) 25:1754-1759, 2000

21. Ikuta K, Tono O, Oga M: Clinical outcome of microendoscopic posterior decompression for spinal stenosis associated with degenerative spondylolisthesis--minimum 2-year outcome of 37 patients. Minim Invasive Neurosurg 51:267271,2008

22. Irwin ZN, Hilibrand A, Gustavel M, McLain R, Shaffer W, Myers M, et al: Variation in surgical decision making for degenerative spinal disorders. Part I: lumbar spine. Spine (Phila Pa 1976) 30:2208-2213, 2005

23. Javalkar V, Cardenas R, Tawfik TA, Khan IR, Bollam P, Banerjee $\mathrm{AD}$, et al: Reoperations after surgery for lumbar spinal stenosis. World Neurosurg 75:737-742, 2011

24. Katz JN, Harris MB: Clinical practice. Lumbar spinal stenosis. N Engl J Med 358:818-825, 2008

25. Katz JN, Lipson SJ, Lew RA, Grobler LJ, Weinstein JN, Brick GW, et al: Lumbar laminectomy alone or with instrumented or noninstrumented arthrodesis in degenerative lumbar spinal stenosis. Patient selection, costs, and surgical outcomes. Spine (Phila Pa 1976) 22:1123-1131, 1997

26. Kawaguchi Y, Kanamori M, Ishihara H, Ohmori K, Fujiuchi Y, Matsui H, et al: Clinical symptoms and surgical outcome in lumbar spinal stenosis patients with neuropathic bladder. J Spinal Disord 14:404-410, 2001

27. Kelleher MO, Timlin M, Persaud O, Rampersaud YR: Success and failure of minimally invasive decompression for focal lumbar spinal stenosis in patients with and without deformity. Spine (Phila Pa 1976) 35:E981-E987, 2010

28. Khoo LT, Fessler RG: Microendoscopic decompressive laminotomy for the treatment of lumbar stenosis. Neurosurgery 51 (5 Suppl):S146-S154, 2002

29. Kim CH, Chung CK, Park CS, Choi B, Hahn S, Kim MJ, et al: Reoperation rate after surgery for lumbar spinal stenosis without spondylolisthesis: a nationwide cohort study. Spine J 13:1230-1237, 2013

30. Kleeman TJ, Hiscoe AC, Berg EE: Patient outcomes after minimally destabilizing lumbar stenosis decompression: the "port-hole" technique. Spine (Phila Pa 1976) 25:865-870, 2000
31. Lee KK, Teo EC, Qiu TX, Yang K: Effect of facetectomy on lumbar spinal stability under sagittal plane loadings. Spine (Phila Pa 1976) 29:1624-1631, 2004

32. Lin SM, Tseng SH, Yang JC, Tu CC: Chimney sublaminar decompression for degenerative lumbar spinal stenosis. J Neurosurg Spine 4:359-364, 2006

33. Lurie JD, Tosteson TD, Tosteson A, Abdu WA, Zhao W, Morgan TS, et al: Long-term outcomes of lumbar spinal stenosis: eight-year results of the Spine Patient Outcomes Research Trial (SPORT). Spine (Phila Pa 1976) 40:63-76, 2015

34. Malmivaara A, Slätis P, Heliövaara M, Sainio P, Kinnunen $\mathrm{H}$, Kankare J, et al: Surgical or nonoperative treatment for lumbar spinal stenosis? A randomized controlled trial. Spine (Phila Pa 1976) 32:1-8, 2007

35. Mariconda M, Fava R, Gatto A, Longo C, Milano C: Unilateral laminectomy for bilateral decompression of lumbar spinal stenosis: a prospective comparative study with conservatively treated patients. J Spinal Disord Tech 15:39-46, 2002

36. Martin BI, Mirza SK, Comstock BA, Gray DT, Kreuter W, Deyo RA: Reoperation rates following lumbar spine surgery and the influence of spinal fusion procedures. Spine (Phila Pa 1976) 32:382-387, 2007

37. Minamide A, Yoshida M, Yamada H, Nakagawa Y, Kawai M, Maio K, et al: Endoscope-assisted spinal decompression surgery for lumbar spinal stenosis. J Neurosurg Spine 19:664-671, 2013

38. Morgalla MH, Noak N, Merkle M, Tatagiba MS: Lumbar spinal stenosis in elderly patients: is a unilateral microsurgical approach sufficient for decompression? J Neurosurg Spine 14:305-312, 2011

39. Nomura H, Yanagisawa Y, Arima J, Oga M: Clinical outcome of microscopic lumbar spinous process-splitting laminectomy: clinical article. J Neurosurg Spine 21:187-194, 2014

40. Oertel MF, Ryang YM, Korinth MC, Gilsbach JM, Rohde $\mathrm{V}$ : Long-term results of microsurgical treatment of lumbar spinal stenosis by unilateral laminotomy for bilateral decompression. Neurosurgery 59:1264-1270, 2006

41. Ofluoğlu AE, Karasu A, Ekinci B, Toplamaoğlu H: The effect of laminectomy on instability in the management of degenerative lumbar stenosis surgery: a retrospective radiographic assessment. Turk Neurosurg 17:178-182, 2007

42. Resnick DK, Watters WC III, Sharan A, Mummaneni PV, Dailey AT, Wang JC, et al: Guideline update for the performance of fusion procedures for degenerative disease of the lumbar spine. Part 9: lumbar fusion for stenosis with spondylolisthesis. J Neurosurg Spine 21:54-61, 2014

43. Robertson PA, Grobler LJ, Novotny JE, Katz JN: Postoperative spondylolisthesis at L4-5. The role of facet joint morphology. Spine (Phila Pa 1976) 18:1483-1490, 1993

44. Sharma M, Langrana NA, Rodriguez J: Role of ligaments and facets in lumbar spinal stability. Spine (Phila Pa 1976) 20:887-900, 1995

45. Tai CL, Hsieh PH, Chen WP, Chen LH, Chen WJ, Lai PL: Biomechanical comparison of lumbar spine instability between laminectomy and bilateral laminotomy for spinal stenosis syndrome - an experimental study in porcine model. BMC Musculoskelet Disord 9:84, 2008

46. Thomas NW, Rea GL, Pikul BK, Mervis LJ, Irsik R, McGregor JM: Quantitative outcome and radiographic comparisons between laminectomy and laminotomy in the treatment of acquired lumbar stenosis. Neurosurgery 41:567-575, 1997

47. Thomé C, Zevgaridis D, Leheta O, Bäzner H, Pöckler-Schöniger C, Wöhrle J, et al: Outcome after less-invasive decompression of lumbar spinal stenosis: a randomized comparison of unilateral laminotomy, bilateral laminotomy, and laminectomy. J Neurosurg Spine 3:129-141, 2005

48. Weinstein JN, Lurie JD, Olson PR, Bronner KK, Fisher ES: 
United States' trends and regional variations in lumbar spine surgery: 1992-2003. Spine (Phila Pa 1976) 31:2707-2714, 2006

49. Weinstein JN, Tosteson TD, Lurie JD, Tosteson A, Blood E, Herkowitz H, et al: Surgical versus nonoperative treatment for lumbar spinal stenosis four-year results of the Spine Patient Outcomes Research Trial. Spine (Phila Pa 1976) 35:1329-1338, 2010

50. Weinstein JN, Tosteson TD, Lurie JD, Tosteson AN, Blood E, Hanscom B, et al: Surgical versus nonsurgical therapy for lumbar spinal stenosis. N Engl J Med 358:794-810, 2008

51. Wong AP, Smith ZA, Lall RR, Bresnahan LE, Fessler RG: The microendoscopic decompression of lumbar stenosis: a review of the current literature and clinical results. Minim Invasive Surg 2012:325095, 2012

52. Yagi M, Okada E, Ninomiya K, Kihara M: Postoperative outcome after modified unilateral-approach microendoscopic midline decompression for degenerative spinal stenosis. J Neurosurg Spine 10:293-299, 2009

53. Yone K, Sakou T: Usefulness of Posner's definition of spinal instability for selection of surgical treatment for lumbar spinal stenosis. J Spinal Disord 12:40-44, 1999
54. Young S, Veerapen R, O'Laoire SA: Relief of lumbar canal stenosis using multilevel subarticular fenestrations as an alternative to wide laminectomy: preliminary report. Neurosurgery 23:628-633, 1988

\section{Disclosure}

Dr. Shamji is a consultant for Medtronic Sofamor Danek with no relevant conflicts of interest in this work. There was no funding received by the authors for this systematic review.

\section{Author Contributions}

Conception and design: all authors. Acquisition of data: Shamji, Guha. Analysis and interpretation of data: Shamji, Guha. Drafting the article: Shamji, Guha. Critically revising the article: all authors. Reviewed submitted version of manuscript: all authors.

\section{Correspondence}

Mohammed F. Shamji, Division of Neurosurgery, Toronto Western Hospital, WW4-446 - 399 Bathurst St., Toronto, ON M5T 2S8, Canada. email: mohammed.shamji@uhn.ca. 